\title{
RESEARCH
}

Open Access

\section{D-dimer as a biomarker for disease severity and mortality in COVID-19 patients: a case control study}

Yumeng $\mathrm{Yao}^{1 \dagger}{ }^{\dagger}$, Jiatian $\mathrm{CaO}^{2 \dagger}$, Qingqing Wang ${ }^{1}$, Qingfeng Shi ${ }^{3}$, Kai Liư ${ }^{4}$, Zhe Luo ${ }^{4}$, Xiang Chen ${ }^{3}$, Sisi Chen ${ }^{5}$, Kaihuan $\mathrm{Yu}^{6}$, Zheyong Huang ${ }^{2^{*}}$ (D) and Bijie $\mathrm{Hu}^{1,3^{*}}$

\begin{abstract}
Background: Over 5,488,000 cases of coronavirus disease-19 (COVID-19) have been reported since December 2019. We aim to explore risk factors associated with mortality in COVID-19 patients and assess the use of D-dimer as a biomarker for disease severity and clinical outcome.

Methods: We retrospectively analyzed the clinical, laboratory, and radiological characteristics of 248 consecutive cases of COVID-19 in Renmin Hospital of Wuhan University, Wuhan, China from January 28 to March 08, 2020. Univariable and multivariable logistic regression methods were used to explore risk factors associated with inhospital mortality. Correlations of D-dimer upon admission with disease severity and in-hospital mortality were analyzed. Receiver operating characteristic curve was used to determine the optimal cutoff level for D-dimer that discriminated those survivors versus non-survivors during hospitalization.

Results: Multivariable regression that showed D-dimer $>2.0 \mathrm{mg} / \mathrm{L}$ at admission was the only variable associated with increased odds of mortality [OR 10.17 (95\% Cl 1.10-94.38), $P=0.041]$. D-dimer elevation ( $\geq 0.50 \mathrm{mg} / \mathrm{L}$ ) was seen in 74.6\% (185/248) of the patients. Pulmonary embolism and deep vein thrombosis were ruled out in patients with high probability of thrombosis. D-dimer levels significantly increased with increasing severity of COVID-19 as determined by clinical staging (Kendall's tau- $b=0.374, P=0.000$ ) and chest $C T$ staging (Kendall's tau- $b=0.378, P=$ 0.000). In-hospital mortality rate was 6.9\%. Median $D$-dimer level in non-survivors $(n=17)$ was significantly higher than in survivors $(n=231)$ [6.21 (3.79-16.01) $\mathrm{mg} / \mathrm{L}$ versus $1.02(0.47-2.66) \mathrm{mg} / \mathrm{L}, P=0.000]$. D-dimer level of $>2.14$ $\mathrm{mg} / \mathrm{L}$ predicted in-hospital mortality with a sensitivity of $88.2 \%$ and specificity of $71.3 \%$ (AUC $0.85 ; 95 \% \mathrm{Cl}=0.77-$ 0.92).
\end{abstract}

Conclusions: D-dimer is commonly elevated in patients with COVID-19. D-dimer levels correlate with disease severity and are a reliable prognostic marker for in-hospital mortality in patients admitted for COVID-19.

Keywords: D-dimer, Coronavirus disease-19, Biomarker, Severity, Mortality

\footnotetext{
* Correspondence: zheyonghuang@126.com; hubijie@vip.sina.com

†Yumeng Yao and Jiatian Cao contributed equally to this work.

${ }^{2}$ Shanghai Institute of Cardiovascular Diseases, Zhongshan Hospital, Fudan

University, 180 Feng Lin Road, Shanghai 200032, China

'Department of Infectious Diseases, Zhongshan Hospital, Fudan University,

180 Feng Lin Road, Shanghai 200032, China

Full list of author information is available at the end of the article
}

(c) The Author(s). 2020 Open Access This article is licensed under a Creative Commons Attribution 4.0 International License, which permits use, sharing, adaptation, distribution and reproduction in any medium or format, as long as you give appropriate credit to the original author(s) and the source, provide a link to the Creative Commons licence, and indicate if changes were made. The images or other third party material in this article are included in the article's Creative Commons licence, unless indicated otherwise in a credit line to the material. If material is not included in the article's Creative Commons licence and your intended use is not permitted by statutory regulation or exceeds the permitted use, you will need to obtain permission directly from the copyright holder. To view a copy of this licence, visit http://creativecommons.org/licenses/by/4.0/ The Creative Commons Public Domain Dedication waiver (http://creativecommons.org/publicdomain/zero/1.0/) applies to the data made available in this article, unless otherwise stated in a credit line to the data. 


\section{Background}

Coronavirus disease-19 (COVID-19) is the disease caused by 2019-nCoV/SARS-CoV-2, a novel $\beta$ coronavirus of group $2 \mathrm{~B}[1]$. The illness ranges from asymptomatic or mild infection to severe respiratory tract infections in humans such as those seen in severe acute respiratory syndrome (SARS) and Middle East respiratory syndrome (MERS). Presentations include fever, coughing, dyspnea, watery diarrhea, myalgia, severe lymphopenia, prolonged coagulation profiles, cardiac disease, and sudden death [2,3].

Since the emergence in Wuhan, Hubei province, China in December 2019, COVID-19 has increased rapidly in China and progressed worldwide. On January 30, 2020, WHO declared the outbreak as a Public Health Emergency of International Concern (PHEIC). As of May 27, 5,488,825 cases have been confirmed globally, including in Americas, Europe, Eastern Mediterranean, South-East Asia, and Africa, and 349,095 deaths have been reported [4]. Coagulopathy was reported, and D-dimer elevations were seen in $3.75-68.0 \%$ of the COVID-19 patients [2, 5, 6]. Previous studies in community-acquired pneumonia (CAP) and chronic obstructive pulmonary disease (COPD) patients have shown that $\mathrm{D}$-dimer level is higher in severe cases and may be used as a prognostic biomarker [7-9], and D-dimer $>1 \mu \mathrm{g} / \mathrm{ml}$ is one of the risk factors for mortality in adult inpatients with COVID-19 [6]. However, the role of D-dimer in COVID-19 patients has not been fully investigated. In this study, we showed D-dimer levels in patient groups stratified by clinical severities, imaging staging, in-hospital death, and assessed the role of D-dimer as a biomarker for disease severity and clinical outcome.

\section{Methods}

\section{Patients}

We enrolled patients of confirmed COVID-19 referred to the Renmin Hospital of Wuhan University (Wuhan, China), a designated center prioritized in treating critical illness, from January 28 to March 08, 2020. Confirmed cases were defined as those with epidemiological history, consistent with two clinical manifestations, and microbiological evidence (respiratory or blood specimens positive for SARS-CoV-2 by real-time reverse transcription polymerase chain reaction (RT-PCR) assay or virus gene sequencing) according to the Novel Coronavirus Pneumonia Diagnosis and Treatment Guideline (6th ed.) (in Chinese) published by the National Health Commission of China [10]. Symptom onset is determined by the earliest clinical manifestations consistent with COVID-19, such as fever, cough, dyspnea, muscle pain, diarrhea, and fatigue, recorded in medical history taken upon admission. Exclusion criteria included pregnancy, cancer, hematologic malignancy, chronic liver disease, acute coronary syndrome, surgery or trauma within 30 days, and patients without D-dimer testing upon admission. We retrospectively collected demographic, clinical data, laboratory parameters, chest CT imaging, and prognosis through electronic nursing and medical records using standardized data collection form. This study was approved by the institutional ethics board of Renmin Hospital of Wuhan University (No. WDRY2020K048).

\section{Laboratory and imaging methods}

Complete blood count, coagulation profile, renal and liver function, creatine kinase, electrolytes, myocardial enzymes, CD4 and CD8 cell counts, C-reactive protein, and procalcitonin were collected routinely on admission. D-dimer level is tested using immunoturbidimetric assay with reference range of 0-0.50 mg/L (Sysmex, CS5100). Doppler ultrasound and CT pulmonary angiography were done for any patients with high clinical suspicion of pulmonary embolism/deep vein thrombosis (PE/ DVT). Chest CT scan was done for all inpatients.

\section{Severity assessment}

Clinically, severity of the COVID-19 patients was classified into mild, moderate, severe, and critically ill according to the Novel Coronavirus Pneumonia Diagnosis and Treatment Guideline (6th ed.) by the National Health Commission of China (Supplement table 1) [10]. Radiologically, the area of affected lungs consistent with viral pneumonia in each patient's first chest CT after admission was measured and classified into $\leq 30 \%, 31-50 \%$, and $\geq 50 \%$ of total lung area. According to oxygenation index (OI) at admission, patients were grouped into 4 groups (group 1 , OI $\geq$ $400 \mathrm{mmHg}$; group 2, OI 300-399 $\mathrm{mmHg}$; group 3, OI 200-299 mmHg; group 4, OI < $200 \mathrm{mmHg}$ ). The scores of SOFA, qSOFA, ITSH for disseminated intravascular coagulation (DIC), CURB-65 for communityacquired pneumonia and Wells' rule [11], and the revised Geneva score [12] for assessing pulmonary embolism (PE) risk for each patient were documented.

\section{Statistics}

Continuous data accorded with normal distribution and homogeneity of variance were expressed as mean \pm SD and compared by independent samples $t$ test or expressed as median (25-75th percentile) and compared by Wilcoxon rank sum test. Categorical variables were expressed as number (percentage) and compared by Chi-square tests or Fisher's exact test. To explore the risk factors associated with mortality, univariable and 
multivariable logistic regression models were used. Considering the total number of deaths $(n=17)$ in our study and to avoid overfitting in the model, we excluded variables from the univariable analysis if their betweengroup differences were not significant and if the number of events was too small to calculate odds ratios. Therefore, we chose age, SOFA, qSOFA, ISTH-DIC score, CURB-65, lymphocyte count, and D-dimer as the seven variables for our multivariable logistic regression model. Correlations of D-dimer with clinical staging, chest CT staging, oxygenation index, and in-hospital mortality were evaluated by Kendall's tau-b coefficient analysis. To assess the predictive value of $\mathrm{D}$-dimer for mortality, receiver operating characteristic (ROC) analysis was conducted with calculations of the area under the ROC curve (AUC), sensitivity and specificity. Statistical analyses were performed with SPSS (v.22.0; SPSS Inc., Chicago, IL, USA), and $P$ value less than 0.05 was considered statistically significant.

\section{Results}

As a designated referral center for the novel coronavirus infection, all the patients hospitalized were confirmed with RT-PCR. After excluding subjects using the exclusion criteria, we included 248 consecutive inpatients between January 28 and March 8, 2020, in the final analysis. The mean age of the 248 patients was $63.0 \pm$ 13.4 years, ranging from 27 to 88 years. The average time from symptom onset to admission was $11.5 \pm 5.1$ days. Nearly one third of the patients had comorbidities, with hypertension being the most common (31.5\%), followed by diabetes mellitus (17.7\%). Mild to moderate cases, severe cases, and critically ill cases accounted for 36.3\%, $43.5 \%$, and $20.2 \%$ of the patients, respectively. Average length of hospital stay was $30.8 \pm 12.4$ days. Using the revised Geneva score, none belonged to the high probability group for risk of PE. Four patients belonged to the high probability group using the Wells' rule. Fortunately, they were ruled out of PE/VTE by Doppler ultrasonography and CT pulmonary angiography. Seventeen patients died during hospitalization. D-dimer elevation $(\geq 0.50 \mathrm{mg} / \mathrm{L})$ was seen in $74.6 \%(185 / 248)$ of the patients.

Since all patients with normal D-dimer $(<0.5 \mathrm{mg} / \mathrm{L})$ at admission survived, patients were grouped into Ddimer levels of $<1,1-2$, and $>2 \mathrm{mg} / \mathrm{L}$ in the univariable and multivariable logistic regression models (Table 1). In univariable analysis, age, SOFA score, qSOFA score, ISTH-DIC score, CURB-65, lymphocytopenia, and elevated D-dimer were associated with death. When these variables were included in the multivariable logistic regression model, D-dimer greater than $2 \mathrm{mg} / \mathrm{L}$ at admission was the only variable associated with increased odds of mortality [OR 10.17 (95\% CI 1.10-94.38), $P=0.041$ ].

The comparison of demographic and clinical characteristics between the normal D-dimer group and elevated D-dimer group are shown in Table 2. Major laboratory markers and chest imaging features upon admission were recorded (Table 3). 35.5\%, 31.0\%, and $33.5 \%$ of the patients had affected lungs of $\leq 30 \%$, 31$50 \%$, and $\geq 50 \%$ of the total area. The predominant changes seen were ground glass opacity (54.0\%), followed by patchy consolidation (21.4\%), fibrous stripes $(12.9 \%)$, and irregular consolidated nodules (11.7\%). $67.7 \%$ of the patients received oxygen therapy, including nasal cannula/face mask (52.0\%), non-invasive mechanical ventilation $(10.5 \%)$, invasive mechanical ventilation (5.2\%), and extracorporeal membrane oxygenation in one patient. Anticoagulation therapy was prescribed in $34.3 \%$ of the cases.

The distributions of D-dimer levels among patients with different clinical staging, chest CT staging, and who survived and deceased during hospitalization are presented in Figs. 1, 2, 3, and 4. On admission, D-dimer levels significantly increased with increasing severity of COVID-19 as determined by clinical staging (Kendall's tau-b $=0.374, P=0.000$ ), chest $\mathrm{CT}$ staging (Kendall's tau-b $=0.378, P=0.000$ ), and oxygenation index (Kendall's tau-b $=0.392, P=0.000)$. Median D-dimer levels showed an about 7 -fold increase from moderate to critically ill patients $(4.76[2.02-13.30] \mathrm{mg} / \mathrm{L}$ versus 0.6 [0.33-1.49] mg/L, $P=0.000$ ), a 5 -fold increase from patients with $\leq 30 \%$ affected lung area to $\geq 50 \%$ change (3.93 [1.28-12.31] $\mathrm{mg} / \mathrm{L}$ versus 0.6 [0.33-1.42], $P=$ 0.042 ), and an over 9-fold increase from oxygenation index groups 1 to 4 ( 6.17 [1.75-14.20] $\mathrm{mg} / \mathrm{L}$ versus 0.64 [0.46-1.39] mg/L, $P=0.000$ ). All of those who did not survive had increased D-dimer level upon admission. When compared between patients who survived and who died during hospitalization, a significantly higher Ddimer level was detected in non-survivors versus survivors $(6.21[3.79-16.01] \mathrm{mg} / \mathrm{L}$ versus $1.02[0.47-2.66]$ $\mathrm{mg} / \mathrm{L}, P=0047)$.

ROC analysis identified D-dimer $>2.14 \mathrm{mg} / \mathrm{L}$ upon admission as the optimal cutoff level to discriminate survivors from non-survivors (area under the ROC 0.85 , standard error 0.037; 95\% confidence interval [CI] $0.77-0.92, P=0.000$; Fig. 5). $32.7 \%$ of the included patients had a D-dimer of $>2.14 \mathrm{mg} / \mathrm{L}$. For predicting in-hospital mortality, D-dimer level above $2.14 \mathrm{mg} / \mathrm{L}$ had a sensitivity of $88.2 \%$ and specificity of 71.3\% (Table 4).

\section{Discussion}

We demonstrated that in patients diagnosed with COVID-19, D-dimer elevation upon admission was 
Table 1 Risk factors associated with mortality among COVID-19 patients

\begin{tabular}{|c|c|c|c|c|}
\hline & Univariable OR (95\% Cl) & $P$ value & Multivariable OR $(95 \% \mathrm{Cl})$ & $P$ value \\
\hline Age (years) ${ }^{a}$ & $1.08(1.03 \sim 1.14)$ & 0.004 & $1.04(0.98 \sim 1.10)$ & 0.187 \\
\hline Female (vs male) & $2.32(0.83 \sim 6.48)$ & 0.109 & - & - \\
\hline \multicolumn{5}{|c|}{ Comorbidity present (vs not present) } \\
\hline Hypertension & $1.58(0.58 \sim 4.31)$ & 0.374 & - & - \\
\hline Diabetes mellitus & $2.83(0.92 \sim 8.67)$ & 0.069 & - & - \\
\hline SOFA score ${ }^{a}$ & $2.00(1.50 \sim 2.69)$ & 0.000 & $1.44(0.89 \sim 2.33)$ & 0.134 \\
\hline qSOFA score ${ }^{a}$ & $4.47(2.22 \sim 8.99)$ & 0.000 & $2.43(0.87 \sim 6.77)$ & 0.091 \\
\hline \multicolumn{5}{|l|}{ ISTH-DIC score } \\
\hline $0-4$ & 1 (ref) & - & & \\
\hline$\geq 5$ & $24.43(3.77 \sim 158.31)$ & 0.000 & $1.40(0.05 \sim 36.97)$ & 0.84 \\
\hline \multicolumn{5}{|l|}{ CURB-65 score } \\
\hline $0-1$ & 1 (ref) & - & & \\
\hline 2 & $7.59(2.20 \sim 26.25)$ & 0.001 & $1.31(0.26 \sim 6.71)$ & 0.743 \\
\hline$\geq 3$ & $14.43(3.89 \sim 53.56)$ & 0.000 & $0.86(0.09 \sim 8.05)$ & 0.895 \\
\hline \multicolumn{5}{|c|}{ Lymphocyte count $\left(10^{9} / L\right)$} \\
\hline$<1.0$ & $9.85(2.54 \sim 37.80)$ & 0.001 & $1.94(0.24 \sim 15.57)$ & 0.533 \\
\hline$\geq 1.0$ & 1 (ref) & - & & \\
\hline \multicolumn{5}{|c|}{ Alanine aminotransferase (U/L) } \\
\hline$\leq 40 \mathrm{U} / \mathrm{L}$ & 1 (ref) & - & - & - \\
\hline$>40 \mathrm{U} / \mathrm{L}$ & $0.48(0.13 \sim 1.72)$ & 0.259 & - & - \\
\hline \multicolumn{5}{|c|}{ eGFR (ml/[min*1.73m²]) } \\
\hline$<90$ & $1.67(0.60 \sim 4.67)$ & 0.326 & - & - \\
\hline$\geq 90$ & 1 (ref) & - & - & - \\
\hline \multicolumn{5}{|l|}{ Creatine kinase (U/L) } \\
\hline$\leq 198$ & 1 (ref) & - & - & - \\
\hline$>198$ & $2.18(0.58 \sim 8.25)$ & 0.250 & - & - \\
\hline \multicolumn{5}{|l|}{ D-dimer (mg/L) } \\
\hline$<1$ & 1 (ref) & - & 1 (ref) & - \\
\hline $1-2$ & $2.48(0.15 \sim 40.47)$ & 0.524 & $2.21(0.12 \sim 38.61)$ & 0.612 \\
\hline$>2$ & $24.43(3.16 \sim 189.00)$ & 0.002 & $10.17(1.10 \sim 94.38)$ & 0.041 \\
\hline \multicolumn{5}{|c|}{ Anticoagulation therapy } \\
\hline No & 1 (ref) & - & - & \\
\hline Yes & $0.95(0.34 \sim 2.67)$ & 0.93 & - & \\
\hline
\end{tabular}

${ }^{a}$ Per 1-unit increase

common and was associated with both increased disease severity and in-hospital mortality. D-dimers are one of the fragments produced when plasmin cleaves fibrin to break down clots. The assays are routinely used as part of a diagnostic algorithm to exclude the diagnosis of thrombosis. However, any pathologic or non-pathologic process that increases fibrin production or breakdown also increases plasma D-dimer levels [13]. Examples include deep vein thrombosis/pulmonary embolism, arterial thrombosis, disseminated intravascular coagulation, and conditions such as pregnancy, inflammation, cancer, chronic liver diseases, post trauma and surgery status, and vasculitis. Among adults admitted to the emergency room, infections, instead of VTE/PE, are the most common reason for D-dimer elevation [14]. In the present study, no patient had confirmed PE/DVT, which supports the application of D-dimer in COVID-19 not just as a diagnostic tool for thromboembolism. In addition, only three patients in the elevated D-dimer 
Table 2 Comparison of demographic and clinical characteristics between COVID-19 patients with normal and elevated D-dimers

\begin{tabular}{|c|c|c|c|}
\hline & Normal D-dimer, $n=63$ & Elevated D-dimer, $n=185$ & $P$ value \\
\hline Age (years) & $58.0 \pm 14.4$ & $64.6 \pm 12.6$ & 0.001 \\
\hline Male gender (\%) & $32(50.8)$ & $103(55.7)$ & 0.502 \\
\hline \multicolumn{4}{|l|}{ Underlying disease, n (\%) } \\
\hline Hypertension & $12(19.0)$ & $66(35.7)$ & 0.014 \\
\hline Diabetes mellitus & $7(11.1)$ & $37(20.0)$ & 0.319 \\
\hline Coronary artery disease & $3(4.8)$ & $9(4.9)$ & 1.000 \\
\hline Chronic kidney disease & $0(0)$ & $6(3.2)$ & \\
\hline Chronic obstructive pulmonary disease & $0(0)$ & $4(2.2)$ & \\
\hline Time since symptom onset (days) & $10.5 \pm 4.8$ & $11.8 \pm 5.1$ & 0.069 \\
\hline Highest temperature $\left({ }^{\circ} \mathrm{C}\right)$ & $38.1 \pm 0.9$ & $38.1 \pm 1.0$ & 0.948 \\
\hline Clinical staging at admission, $n(\%)$ & & & 0.000 \\
\hline Mild-moderate & $40(63.5)$ & $50(27.0)$ & \\
\hline Severe & $20(31.7)$ & $88(47.6)$ & \\
\hline Critically ill & $3(4.8)$ & $47(25.4)$ & \\
\hline Wells' score, $n(\%)$ & & & 0.230 \\
\hline$<2$ points & $60(95.2)$ & $167(90.3)$ & \\
\hline $2-6$ points & $2(3.2)$ & $15(8.1)$ & \\
\hline$>6$ points & $1(1.6)$ & $3(1.6)$ & \\
\hline Geneva score, n (\%) & & & 0.105 \\
\hline $0-3$ points & $34(54.0)$ & $78(42.2)$ & \\
\hline 4-10 points & $29(46.0)$ & $107(57.8)$ & \\
\hline$\geq 11$ points & 0 & 0 & \\
\hline CURB-65, n (\%) & & & 0.008 \\
\hline Score 0 & $30(47.62)$ & 64 (34.59) & \\
\hline Score 1 & $25(39.68)$ & $68(36.76)$ & \\
\hline Score 2 & $5(7.94)$ & $20(10.81)$ & \\
\hline Score 3 & $3(4.76)$ & $17(9.19)$ & \\
\hline Score 4 & $0(0)$ & $15(8.11)$ & \\
\hline Score 5 & $0(0)$ & $1(0.54)$ & \\
\hline SOFA score & $1(0-1)$ & $1(0-3)$ & 0.007 \\
\hline qSOFA score & $0(0-0)$ & $0(0-1)$ & 0.084 \\
\hline ITSH-DIC score & $0(0-0)$ & $2(2-3)$ & 0.000 \\
\hline Oxygen treatment, n (\%) & & & 0.114 \\
\hline Nasal cannula/face mask & $28(44.4)$ & $101(54.6)$ & \\
\hline NIMV & $2(3.2)$ & $24(13.0)$ & \\
\hline IMV & 0 & $12(6.5)$ & \\
\hline IMV + ECMO & 0 & $1(0.5)$ & \\
\hline Anticoagulation therapy & $12(19.0)$ & $73(39.5)$ & 0.000 \\
\hline Length of hospital stay & $28.3 \pm 12.5$ & $31.7 \pm 12.3$ & 0.078 \\
\hline In-hospital mortality, n (\%) & 0 & $17(9.2)$ & 0.008 \\
\hline
\end{tabular}


Table 3 Comparison of laboratory value and imaging characteristics between COVID-19 patients with normal and elevated D-dimers

\begin{tabular}{|c|c|c|c|}
\hline & Normal D-dimer, $n=63$ & Elevated D-dimer, $n=185$ & $P$ value \\
\hline D-dimer (mg/L) & $0.35(0.23-0.42)$ & $1.69(0.91-5.06)$ & 0.000 \\
\hline $\mathrm{PaO}_{2}(\mathrm{~mm} \mathrm{Hg})$ & $71.63 \pm 14.81$ & $67.37 \pm 14.48$ & 0.147 \\
\hline $\mathrm{PaCO}_{2}(\mathrm{~mm} \mathrm{Hg})$ & $42.5 \pm 8.38$ & $40.13 \pm 7.07$ & 0.112 \\
\hline White blood cell count $\left(\times 10^{9} / \mathrm{L}\right)$ & $4.99 \pm 2.44$ & $6.71 \pm 3.13$ & 0.000 \\
\hline Lymphocyte count $\left(\times 10^{9} / \mathrm{L}\right)$ & $1.3 \pm 0.59$ & $1.03 \pm 0.60$ & 0.002 \\
\hline Neutrophil count $\left(\times 10^{9} / \mathrm{L}\right)$ & $3.12 \pm 2.17$ & $5.11 \pm 3.13$ & 0.000 \\
\hline Hemoglobin (g/L) & $128.7 \pm 13.3$ & $122.6 \pm 16.8$ & 0.010 \\
\hline Platelet count $\left(10^{9} / \mathrm{L}\right)$ & $221.9 \pm 82.9$ & $232.9 \pm 92.6$ & 0.405 \\
\hline CD4 (cells $/ \mathrm{mm}^{3}$ ) & $337(165.5-560.5)$ & $263(109.0-429.5)$ & 0.326 \\
\hline CD8 (cells/mm³) & $229(92-367)$ & $123(48.25-226.25)$ & 0.122 \\
\hline C-reactive protein (mg/L) & $8.5(5-35.85)$ & $48.4(10.98-92.25)$ & 0.000 \\
\hline Procalcitonin (ng/mL) & $0.05(0.03-0.08)$ & $0.08(0.04-0.18)$ & 0.000 \\
\hline Total bilirubin ( $\mu \mathrm{mol} / \mathrm{L})$ & $10.0(6.7-13.0)$ & $11.7(8.6-15.5)$ & 0.050 \\
\hline Combined bilirubin $(\mu \mathrm{mol} / \mathrm{L})$ & $3.4(2.6-5.0)$ & $4.3(3.3-6.1)$ & 0.030 \\
\hline Alanine aminotransferase (U/L) & $21.0(13.0-39.0)$ & $28.5(19.0-55.3)$ & 0.001 \\
\hline Aspartate aminotransferase (U/L) & $24.0(17.0-34.5)$ & $33.5(21.0-49.0)$ & 0.001 \\
\hline Alkaline phosphatase (U/L) & $60.4 \pm 17.0$ & $77.7 \pm 40.3$ & 0.000 \\
\hline Gamma-glutamyl Transferase (U/L) & $30.0(13.5-47.0)$ & $33.5(23.0-68.3)$ & 0.001 \\
\hline Lactate dehydrogenase (IU/L) & $250.41 \pm 90.4$ & $356.11 \pm 185.28$ & 0.000 \\
\hline Serum creatinine (mmol/L) & $64.0(54.0-77.0)$ & $64(52.0-74.0)$ & 0.715 \\
\hline eGFR (ml/[min*1.73m²]) & $97.15 \pm 13.99$ & $88.64 \pm 24.94$ & 0.001 \\
\hline Blood glucose (mmol/L) & $6.49 \pm 3.34$ & $7.12 \pm 3.94$ & 0.257 \\
\hline Creatine kinase $(\mathrm{U} / \mathrm{L})$ & $75.0(50-132.5)$ & $58.5(33-87.5)$ & 0.057 \\
\hline Prothrombin time (s) & $11.7(11.3-12.3)$ & $12.0(11.6-12.7)$ & 0.005 \\
\hline Activated partial thromboplastin time (s) & $28.2(26.4-31.15)$ & $27.3(25.45-29.85)$ & 0.016 \\
\hline Fibrinogen $(g / L)$ & $4.03 \pm 1.33$ & $4.80 \pm 1.57$ & 0.001 \\
\hline Cardiac troponin I ( $\mu \mathrm{g} / \mathrm{L})$ & $0.01(0.01-0.01)$ & $0.01(0.01-0.02)$ & 0.000 \\
\hline B-type natriuretic peptide (pg/mL) & $44.45(18.15-147.6)$ & $222.25(87.69-461.83)$ & 0.000 \\
\hline Area of affected lung on Chest CT, $n(\%)$ & & & 0.000 \\
\hline$\leq 30 \%$ & $37(58.7)$ & $51(27.6)$ & \\
\hline $31-50 \%$ & $16(25.4)$ & $61(33.0)$ & \\
\hline$\geq 50 \%$ & $10(15.9)$ & $73(39.4)$ & \\
\hline Predominant feature on Chest CT, $n(\%)$ & & & 0.287 \\
\hline Ground glass opacities & $40(63.5)$ & $94(50.8)$ & \\
\hline Patchy consolidations & $12(19.1)$ & $41(22.2)$ & \\
\hline Fibrous stripes & $4(6.3)$ & $25(13.5)$ & \\
\hline Irregular solid nodules & $7(11.1)$ & $25(13.5)$ & \\
\hline Pericardial effusion, $n$ (\%) & $1(1.6)$ & $4(2.2)$ & 0.800 \\
\hline
\end{tabular}

group $(3 / 185,1.6 \%)$ with D-dimer levels of $42.8 \mathrm{mg} / \mathrm{L}, 89.0$ $\mathrm{mg} / \mathrm{L}$, and $71.0 \mathrm{mg} / \mathrm{L}$ had ISTH-DIC scores of $\geq 5$, which is laboratory evidence compatible with overt DIC. Thus, the majority of the included patients with $\mathrm{D}$-dimer elevation in our study did not have overt DIC. Due to the retrospective nature of the study and small number of patients with ISTH-DIC score consistent with overt DIC, it is difficult to tell from our data if D-dimer elevation is related with DIC. 


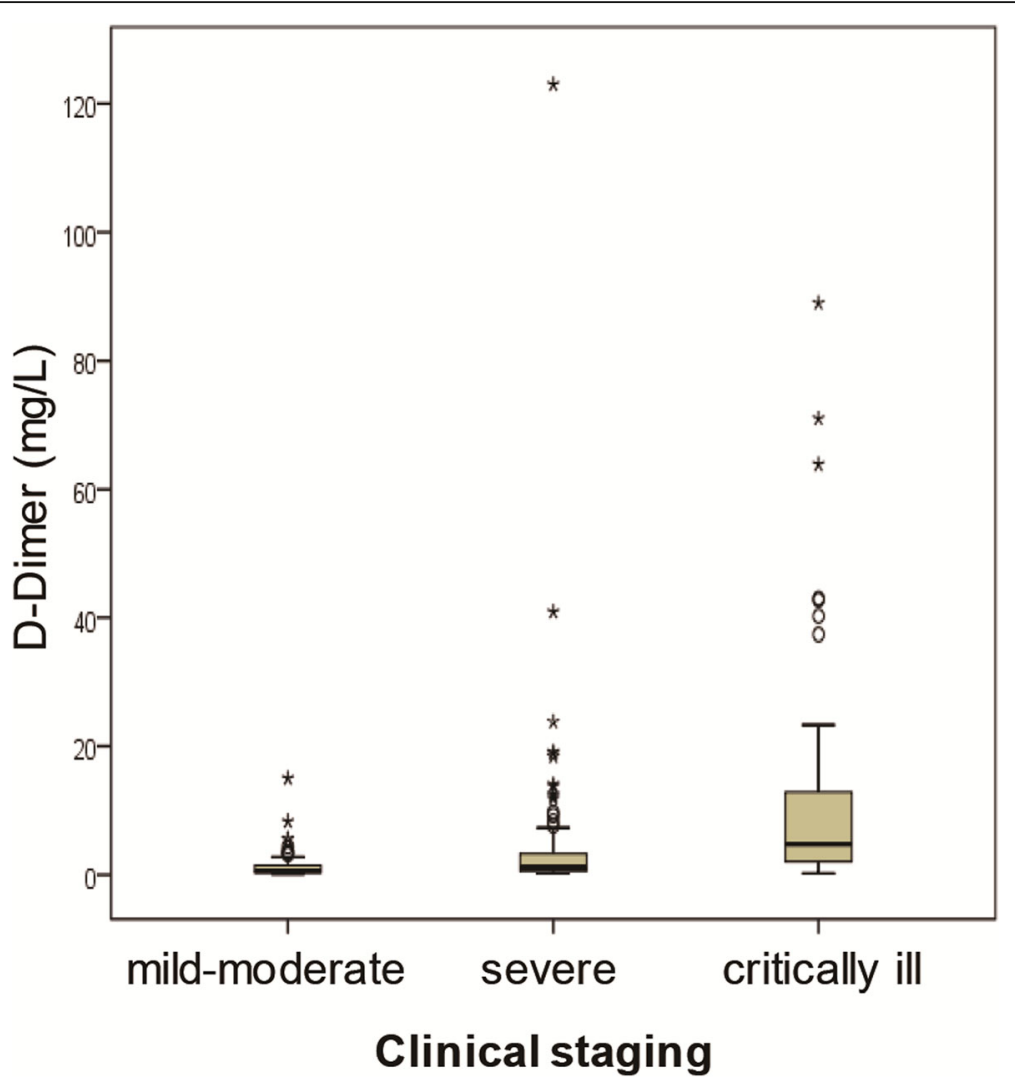

Fig. 1 Correlations of D-dimer levels with clinical staging

Several studies have shown that D-dimer levels are associated with severity of community-acquired pneumonia and clinical outcome [7, 15]. However, Ddimer has not been used as a biomarker for viral pneumonia [16, 17]. Though D-dimer elevation has been observed in articles describing the clinical features of COVID-19, whether the level of D-dimer is a marker of severity has not been examined.

In the present study, there is a significant correlation between D-dimer levels and disease severity stratified by the area of affected lungs on chest CT, oxygenation index, as well as clinical staging according to the interim guideline. In addition, a higher percentage of D-dimer elevation was seen in the present study than previously reported $[2,5]$. This may be due to the higher percentage of severe/critically ill cases referred to our hospital, which is another demonstration of the correlation between D-dimer level and disease severity. This suggests that the assay may be used early as a marker of severity before chest CT scans or as a complement to $\mathrm{CT}$ and clinical staging.

In-hospital mortality was also associated with increased D-dimer levels, suggesting that the assay may be used as a single useful biomarker for clinical outcome in patients with COVID-19. Zhou et al. reported that D-dimer $>1 \mu \mathrm{g} / \mathrm{ml}$ is a risk for mortality [6]. The study objective, design, population, and statistical analysis of Zhou's study and those of ours are different. Zhou's study was a retrospective cohort study to describe risk factors for mortality and clinical course, which included patients who had been discharged or had died by January 31, 2020. The mortality rate was higher compared to that in our study $(28.3 \%$ vs. $6.9 \%)$. To explore risk factor for mortality, Zhou et al. chose age, coronary heart disease, SOFA score, lymphocyte, and D-dimer as variables for multivariable logistic regression model. D-dimer was defined as a categorical variable in the analysis, and levels of $\leq 0.5 \mu \mathrm{g} / \mathrm{L},>0.5$ to $\leq 1 \mu \mathrm{g} / \mathrm{L}$, and $>1 \mu \mathrm{g} / \mathrm{L}$ were chosen. The laboratory method for D-dimer assay was not described. In the present case control study, we focused on the predictive value of $\mathrm{D}$-dimer for in-hospital deaths using receiver operating characteristic analysis. In the analysis, D-dimer is defined as a continuous variable. Testing used immunoturbidimetric assay with reference range of $0-0.50 \mathrm{mg} / \mathrm{L}$ (Sysmex, CS5100). Despite the differences in study design and analysis, the findings and conclusions of 


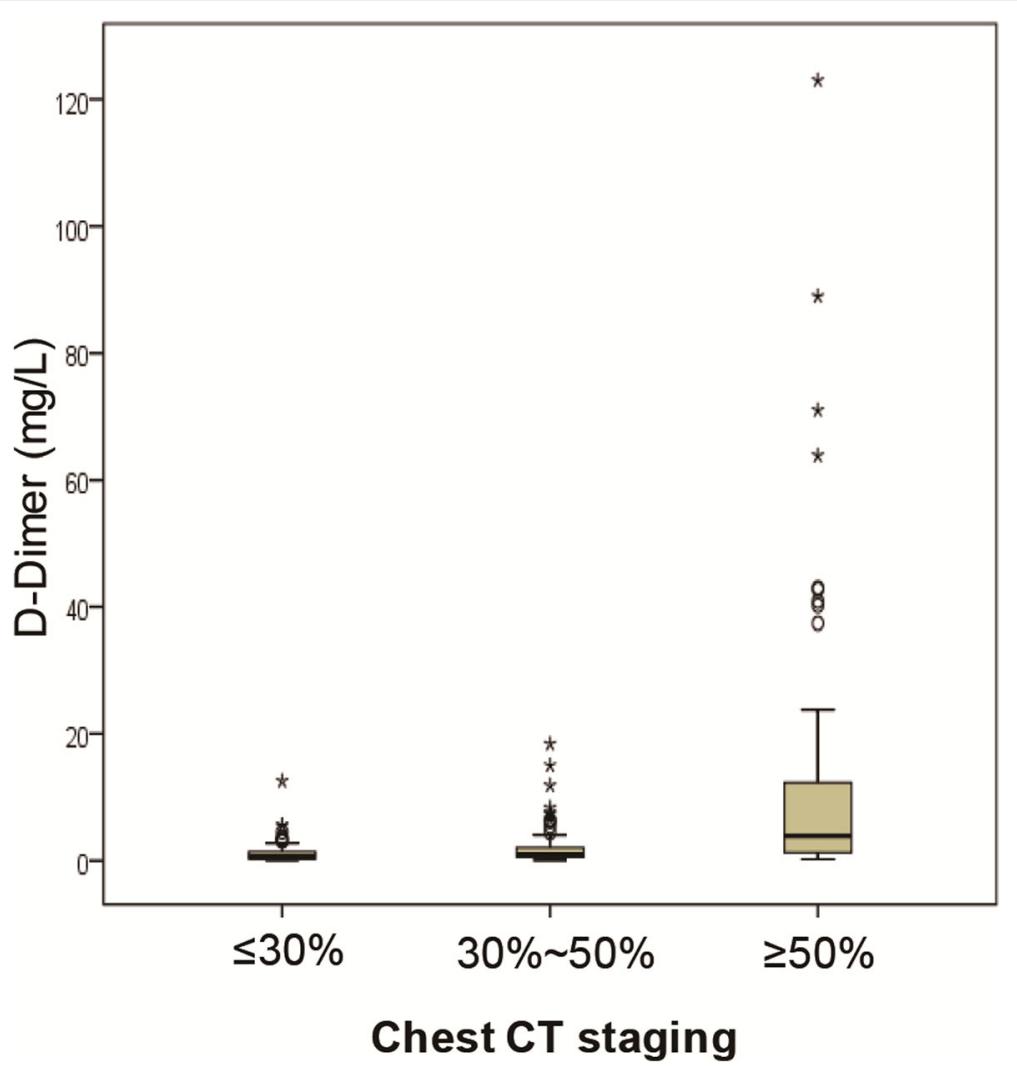

Fig. 2 Correlations of D-dimer levels with chest CT staging according to area of affected lungs

the two studies are not inconsistent. Zhou et al. concluded that the potential risk factors of older age, high SOFA score, and D-dimer greater than $1 \mu \mathrm{g} / \mathrm{L}$ (instead of levels of $\leq 0.5 \mu \mathrm{g} / \mathrm{L}$, or $>0.5$ to $\leq 1 \mu \mathrm{g} / \mathrm{L}$ ) could help clinicians to identify patients with poor prognosis. We found that when using the cutoff value of 2.14, D-dimer levels upon admission for in-hospital mortality has an AUC of 0.846 . The sensitivity and specificity are $88.2 \%$ and $71.3 \%$, respectively. The findings of this present study suggest that an elevated D-dimer level on admission (> $2.14 \mathrm{mg} / \mathrm{L}$ ) may identify patients at higher risk for in-hospital mortality and therefore inform physicians about suitable candidates for intensive care and early intervention.

It is worth noting that the findings suggest associations between D-dimer levels and disease severity and mortality only. Evidence is still lacking as to the causal mechanisms and whether the associations are specific effects of SARS-CoV-2 infection or are consequences of systemic inflammatory response. In SARS-COV-2 infection, dysregulation of coagulation/anti-coagulation cascades results in worsening lung pathology [18]. In influenza, the pathogenesis by augmenting viral replication and immune pathogenesis can be attributed to an aberrant coagulation system, including both the cellular and protein components [19]. The pathological features of COVID-19 include diffuse alveolar damage with cellular fibromyxoid exudates, desquamation of pneumocytes and hyaline membrane formation, pulmonary edema with hyaline membrane formation, and interstitial mononuclear inflammatory infiltrates, dominated by lymphocytes, which greatly resemble those seen in SARS and MERS coronavirus infection [20, 21]. Presumably, the observed D-dimer elevation signify a hyperfibrinolysis state and increased inflammatory burden induced in SARS-COV2 infection. In our logistic regression model to estimate risk factors associated with mortality, systematic anticoagulation therapy was not significantly associated with reduced risk of mortality. However, in a recent observational study including 2773 hospitalized COVID-19 patients, Paranjpe et al. found that treatment dose anticoagulant was associated with a reduced risk of mortality, especially among patients who required mechanical ventilation [22]. And longer duration of treatment was associated with a reduced risk of mortality (adjusted HR of 0.86 per day, 95\% CI $0.82-0.89, p<0.001)$. Whether anticoagulation 


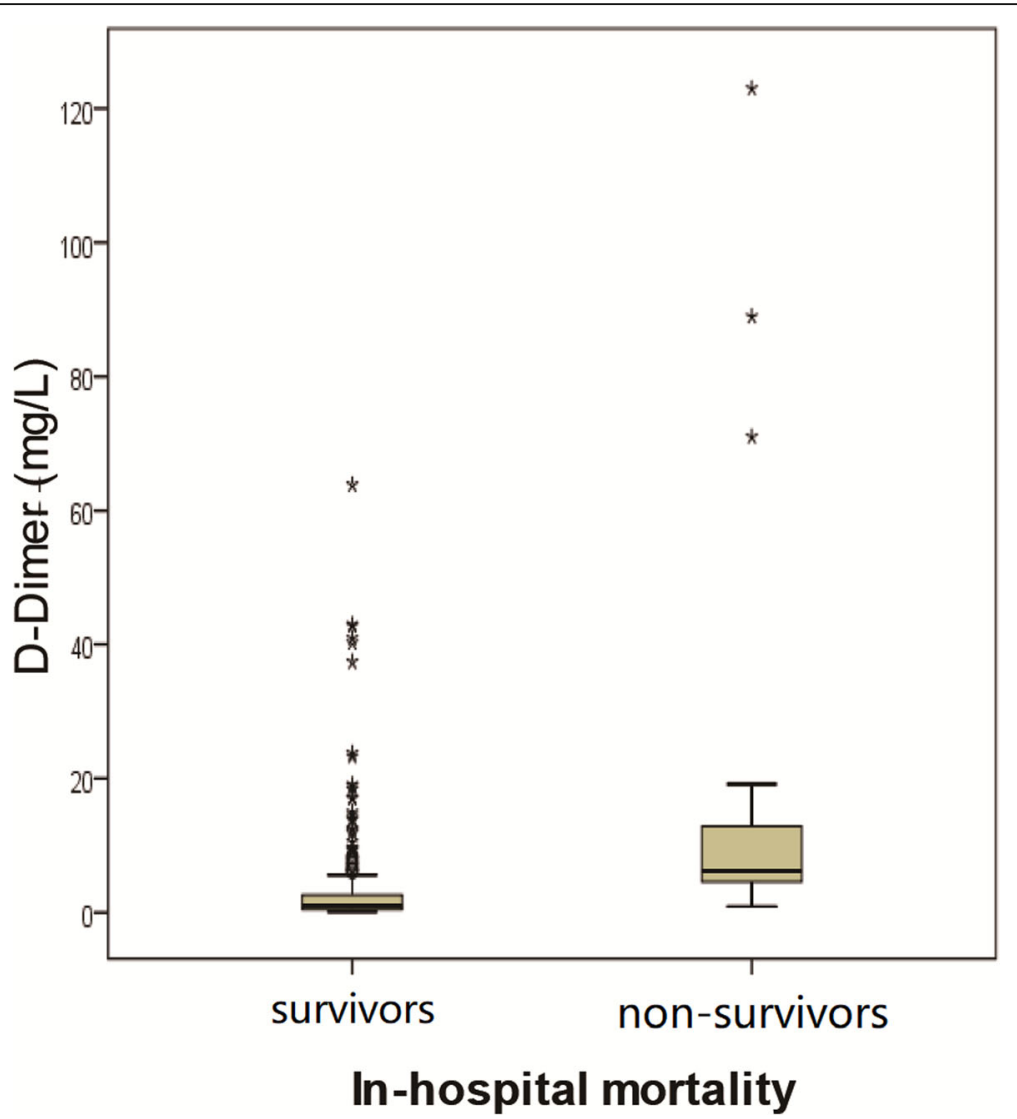

Fig. 3 Correlations of D-dimer levels with in-hospital mortality

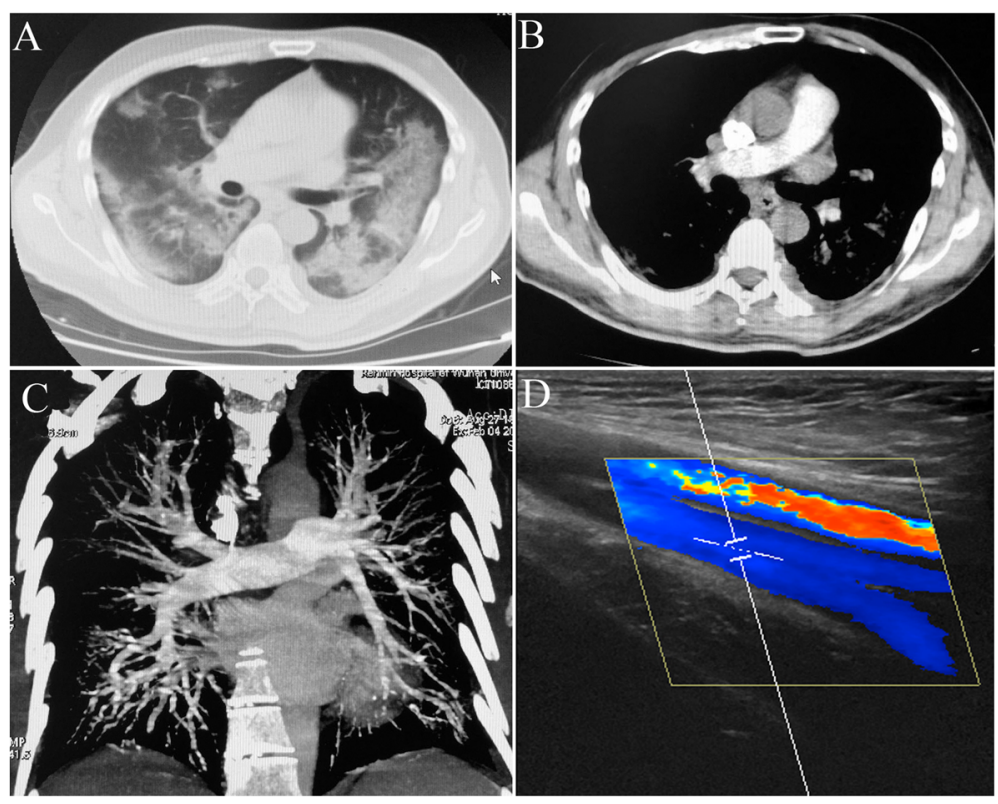

Fig. 4 A 59-year-old male diagnosed with COVID-19 who presented with fever, coughing, and hemoptysis. Chest CT upon admission showing ground glass opacities and patchy consolidation (a). He had an elevated D-dimer level of $9.43 \mathrm{mg} / \mathrm{L}$. Wells' score, Geneva score, and CURB65 score were 7,7 , and 2 respectively. Wells' score suggested high probability of pulmonary embolism. CT pulmonary angiography (b, c) and Doppler ultrasonography (d) were then carried out and ruled out pulmonary embolism and deep vein thrombosis in the lower extremities 


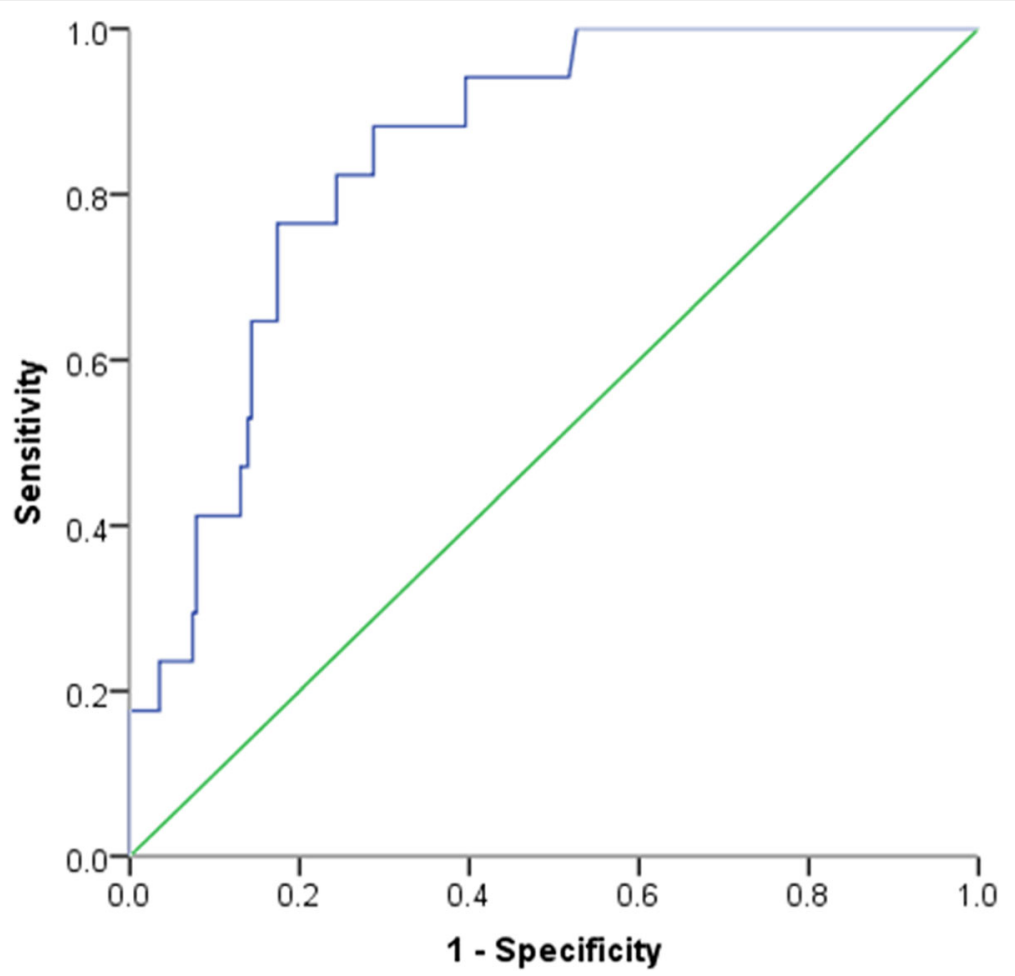

Fig. 5 Receiver operating characteristic curve for D-dimer as parameter for predicting in-hospital mortality in COVID-19 patients

therapy confers a survival benefit in patients hospitalized for COVID-19 needs further research with prospective randomized trials. Currently, the potential benefits need to be weighed against risk of bleeding.

This study has some limitations. First, the current study was done in a single center. The overall mortality (6.9\%) was lower compared with that reported in other studies done in Wuhan $[2,6]$ and considerably higher than those reported by other provinces [5, 23]. Further researches may be needed when extrapolated to wider patient population. Second, the study is retrospective in nature. The patients included were not systematically assessed for the presence of PE/DVT but only when clinically suspected. Third, we did not look into the value of serial D-dimer monitoring in assessing COVID19 patients.

Table 4 Test characteristics of D-dimer for predicting in-hospital mortality with the optimal sensitivity and specificity scores

\begin{tabular}{ll}
\hline Cutoff point for D-dimer (mg/L) & 2.14 \\
\hline Area under curve & 0.85 \\
$95 \% \mathrm{Cl}$ & $0.77-0.92$ \\
Subjects with D-dimer > 2.14 mg/L (\%) & $77(31.2 \%)$ \\
Sensitivity (\%) & 88.2 \\
Specificity (\%) & 71.3 \\
Likelihood ratio & 3.08 \\
\hline
\end{tabular}

\section{Conclusions}

In conclusion, D-dimer levels are commonly elevated in patients infected with SARS-CoV-2. Significantly higher levels are found in those with critical illness and may be used as a prognostic marker for inhospital mortality.

\section{Supplementary information}

Supplementary information accompanies this paper at https://doi.org/10. 1186/s40560-020-00466-Z.

Additional file 1: Supplement table 1. Clinical Classifications of COVID-19.

\section{Abbreviations}

COVID-19: Coronavirus disease-19; SARS: Severe acute respiratory syndrome; MERS: Middle East respiratory syndrome; PHEIC: Public Health Emergency of International Concern; CAP: Community-acquired pneumonia; COPD: Chronic obstructive pulmonary disease; PE: Pulmonary embolism; DVT: Deep vein thrombosis; ISTH: International Society on Thrombosis and Haemostasis;

DIC: Disseminated intravascular coagulation

\section{Acknowledgements}

Not applicable

\section{Authors' contributions}

YY and JC contributed in the conception, design, acquisition and analysis, interpretation of data, and writing of the manuscript. QW, QS, KL, ZL, XC, SC, and $\mathrm{KY}$ contributed in the design, acquisition, and analysis of data. $\mathrm{ZH}$ and $\mathrm{BH}$ contributed to the conception, design of the work, analysis of data, interpretation of data, and revision of the manuscript. All authors have approved the submitted version. All authors have agreed to be personally accountable for the author's own contributions and to ensure that questions 
related to the accuracy or integrity of any part of the work, even ones in which the author was not personally involved, are appropriately investigated and resolved and the resolution documented in the literature.

\section{Funding}

None

Availability of data and materials

The dataset supporting the conclusions of this article is included within the article and its additional files.

\section{Ethics approval and consent to participate}

This study was approved by the institutional ethics board of Renmin Hospital of Wuhan University (No. WDRY2020-K048).

\section{Consent for publication}

Not applicable

\section{Competing interests}

The authors declare that they have no competing interests in this section.

\section{Author details}

'Department of Infectious Diseases, Zhongshan Hospital, Fudan University, 180 Feng Lin Road, Shanghai 200032, China. ${ }^{2}$ Shanghai Institute of Cardiovascular Diseases, Zhongshan Hospital, Fudan University, 180 Feng Lin Road, Shanghai 200032, China. ${ }^{3}$ Department of Infection Control, Zhongshan Hospital, Fudan University, 180 Feng Lin Road, Shanghai 200032, China. ${ }^{4}$ Department of Critical Care Medicine, Zhongshan Hospital, Fudan University, 180 Feng Lin Road, Shanghai 200032, China. ${ }^{5}$ Department of Cardiology, Renmin Hospital, Wuhan University, Gaoxin 6th Road, Donghu High Tech Development Zone, Wuhan City 430200, China. ${ }^{6}$ Department of Hepatobiliary Endoscopic Surgery, Renmin Hospital, Wuhan University, Gaoxin 6th Road, Donghu High Tech Development Zone, Wuhan City 430200, China.

Received: 30 March 2020 Accepted: 29 June 2020

Published online: 10 July 2020

\section{References}

1. Zhou P, Yang X, Wang X, Hu B, Zhang L, Zhang W, Si H, Zhu Y, Li B, Huang $C$, et al. A pneumonia outbreak associated with a new coronavirus of probable bat origin. Nature. 2020;579(7798):270-3.

2. Chen N, Zhou M, Dong X, Qu J, Gong F, Han Y, Qiu Y, Wang J, Liu Y, Wei Y, et al. Epidemiological and clinical characteristics of 99 cases of 2019 novel coronavirus pneumonia in Wuhan, China: a descriptive study. Lancet. 2020; 395(10223):507-13.

3. Huang C, Wang Y, Li X, Ren L, Zhao J, Hu Y, Zhang L, Fan G, Xu J, Gu X, et al. Clinical features of patients infected with 2019 novel coronavirus in Wuhan, China. Lancet (London, England). 2020;395(10223):497-506.

4. Coronavirus disease (COVID-19) Situation Report-128. https://www.who.int/ emergencies/diseases/novel-coronavirus-2019/situation-reports. (Accessed 28 May 2020)

5. Wu J, Liu J, Zhao X, Liu C, Wang W, Wang D, Xu W, Zhang C, Yu J, Jiang B,et al. Clinical Characteristics of Imported Cases of COVID-19 in Jiangsu Province: A Multicenter Descriptive Study. Clin Infect Dis. 2020;29:ciaa199.

6. Zhou F, Yu T, Du R, Fan G, Liu Y, Liu Z, Xiang J, Wang Y, Song B, Gu X, et al. Clinical course and risk factors for mortality of adult inpatients with COVID19 in Wuhan, China: a retrospective cohort study. Lancet. 2020; 395(10229): 1054-62.

7. Querol-Ribelles JM, Tenias JM, Grau E, Querol-Borras JM, Climent JL, Gomez E, Martinez I. Plasma d-dimer levels correlate with outcomes in patients with community-acquired pneumonia. Chest. 2004;126(4):1087-92.

8. Fruchter $\mathrm{O}$, Yigla M, Kramer MR. d-dimer as a prognostic biomarker for mortality in chronic obstructive pulmonary disease exacerbation. Am J Med Sci. 2015;349(1):29-35.

9. Snijders D, Schoorl M, Schoorl M, Bartels PC, van der Werf TS, Boersma WG. D-dimer levels in assessing severity and clinical outcome in patients with community-acquired pneumonia. A secondary analysis of a randomised clinical trial. Eur J Intern Med. 2012;23(5):436-41.
10. Novel Coronavirus Pneumonia Diagnosis and Treatment Guideline (6th ed.) (inChinese). 2020. http://www.nhc.gov.cn/xcs/zhengcwi/202002/8334a8326 dd94d329df351d7da8aefc2.shtml. (Accessed 03 Mar 2020).

11. Wells $P$, Anderson D, Rodger M, Ginsberg J, Kearon C, Gent M, Turpie A, Bormanis J, Weitz J, Chamberlain M, et al. Derivation of a simple clinical model to categorize patients probability of pulmonary embolism: increasing the models utility with the SimpliRED D-dimer. Thromb Haemostasis. 2017; 83(03):416-20

12. Le Gal G, Righini M, Roy PM, Sanchez O, Aujesky D, Bounameaux H, Perrier A. Prediction of pulmonary embolism in the emergency department: the revised Geneva score. Ann Intern Med. 2006;144(3):165-71.

13. Linkins LA, Takach Lapner S. Review of D-dimer testing: good, bad, and ugly. Int J Lab Hematol. 2017;39(S1):98-103.

14. Lippi G, Bonfanti L, Saccenti C, Cervellin G. Causes of elevated D-dimer in patients admitted to a large urban emergency department. Eur J Intern Med. 2014;25(1):45-8.

15. Dai R, Kong Q, Mao B, Xu W, Tao R, Wang X, Kong Q, Xu J. The mortality risk factor of community acquired pneumonia patients with chronic obstructive pulmonary disease: a retrospective cohort study. BMC Pulm Med. 2018;18(1):12

16. Guo L, Wei D, Zhang X, Wu Y, Li Q, Zhou M, Qu J. Clinical features predicting mortality risk in patients with viral pneumonia: the MuLBSTA score. Front Microbiol. 2019;10:2752.

17. Yoon H, Jhun BW, Kim SJ, Kim K. Clinical characteristics and factors predicting respiratory failure in adenovirus pneumonia. Respirology. 2016; 21(7):1243-50

18. Gralinski LE, Baric RS. Molecular pathology of emerging coronavirus infections. J Pathol. 2015;235(2):185-95.

19. Yang $\mathrm{Y}$, Tang $\mathrm{H}$. Aberrant coagulation causes a hyper-inflammatory response in severe influenza pneumonia. Cell Mol Immunol. 2016;13(4): 432-42.

20. Xu Z, Shi L, Wang Y, Zhang J, Huang L, Zhang C, Liu S, Zhao P, Liu H, Zhu L, et al. Pathological findings of COVID-19 associated with acute respiratory distress syndrome. Lancet Respir Med. 2020;8(4):420-2.

21. Channappanavar R, Perlman S. Pathogenic human coronavirus infections: causes and consequences of cytokine storm and immunopathology. Semin Immunopathol. 2017;39(5):529-39.

22. Paranjpe I, Fuster V, Lala A, Russak A, Glicksberg BS, Levin MA, Charney AW, Narula J, Fayad ZA, Bagiella E, et al. Association of treatment dose anticoagulation with in-hospital survival among hospitalized patients with CovID-19. J Am Coll Cardiol. 2020:76(1):122-4.

23. Tian S, Hu N, Lou J, Chen K, Kang X, Xiang Z, Chen H, Wang D, Liu N, Liu D, et al. Characteristics of COVID-19 infection in Beijing. J Infect. 2020;80(4): 401-6.

\section{Publisher's Note}

Springer Nature remains neutral with regard to jurisdictional claims in published maps and institutional affiliations.

Ready to submit your research? Choose BMC and benefit from:

- fast, convenient online submission

- thorough peer review by experienced researchers in your field

- rapid publication on acceptance

- support for research data, including large and complex data types

- gold Open Access which fosters wider collaboration and increased citations

- maximum visibility for your research: over $100 \mathrm{M}$ website views per year

At BMC, research is always in progress.

Learn more biomedcentral.com/submissions 